\title{
KNOWLEDGE AND BARRIERS TO USE OF LOW-OSMOLARITY ORAL REHYDRATION SOLUTION AND ZINC SUPPLEMENTATION IN THE MANAGEMENT OF CHILDHOOD DIARRHEA AMONG PRIMARY HEALTH CARE PROVIDERS IN IMO STATE, NIGERIA
}

\author{
Ogugua Jane Uzoma ${ }^{1}$ and Chiejina Edith Nkechi ${ }^{*}$ \\ ${ }^{1}$ Catholic Secretariat of Nigeria, Plot 459 Cadastral Zone B2 Durumi 1, Garki, Abuja FCT, \\ Nigeria. Email: jogugua@ccfng.org \\ ${ }^{* 2}$ Department of Nursing Science, Faculty of Health Sciences and Technology, Nnamdi \\ Azikiwe University Awka (Nnewi Campus), Anambra State, Nigeria. \\ Email: nkechichiejina@yahoo.com; Phone no: +2348037463279
}

Cite this article:

Ogugua J.U., Chiejina E.N. (2021), Knowledge and Barriers to Use of LowOsmolarity Oral Rehydration Solution and Zinc

Supplementation in the Management of Childhood Diarrhea Among Primary Health Care Providers in Imo State, Nigeria. African Journal of Biology and Medical Research 4(3), 79-91. DOI: 10.52589/AJBMRBDDCNOIZ.

\section{Manuscript History \\ Received: 25 June 2021 \\ Accepted: 21 July 2021 \\ Published: 30 July 2021}

Copyright $(02020$ The Author(s). This is an Open Access article distributed under the terms of Creative Commons AttributionNonCommercial-NoDerivative 4.0 International (CC BY-NC-ND 4.0 ), which permits anyone to share, use, reproduce and redistribute in any medium, provided the original author and source are credited.
ABSTRACT: Low-Osmolarity Oral Rehydration Solution (L-ORS) and zinc supplementation remain the recommended gold standard for the management of childhood diarrhoea. However, since 2005, there has been little or no progress in increasing the use of L-ORS and zinc supplementation in the management of children under 5 years with diarrhoea. The study, therefore, assessed the knowledge and barriers to the use of low osmolarity ORS and zinc supplementation among primary healthcare providers. The study was a descriptive crosssectional design carried out among health care providers working in government-owned primary health centres across the 27 LGAs of Imo State Nigeria. A pre-tested structured questionnaire was used to collect data from randomly selected 340 health care providers. Data was analysed using descriptive statistics and a chi-square test. Out of the 340 healthcare providers who participated in the study, a higher proportion of respondents demonstrated a moderate level of knowledge (75.86\%), which was reflected in their moderate extent of use of L-ORS and zinc supplementation in the management of childhood diarrhoea. Major barriers contributing to the suboptimal use of L-ORS and zinc included poor availability of L-ORS and zinc supplementation (85.9\%), limited training and re-training of health care workers (60.9\%) and poor communication of current public trends among health providers (81.5\%). Findings from the study also indicated that the level of knowledge on the use of L-ORS - zinc and cadre of the health providers were significantly associated with the use of L-ORS and zinc: p-value 0.01 , p-value $<0.01$ respectively. Despite the moderate level of knowledge on the use of L-ORS and zinc, there still remained identifiable knowledge gaps on key factors underlying the use of the recommended L-ORS and zinc, hence there is a need for continuous training and re-training programs for health care workers to improve their knowledge and skillsets towards promoting sustainable use of Low ORS and Zinc supplementation in the management of childhood diarrhoea.

KEYWORDS: Low-Osmolarity ORS, Zinc Supplementation, Knowledge, Barriers, Diarrhea 


\section{INTRODUCTION}

\section{Background of the Study}

Oral rehydration salt (ORS) and other components for clinical management of diarrhoea have made a significant contribution to reducing deaths from diarrhoea in the past years; however, after 20 years of research to improve ORS, two advances in managing diarrhoeal disease in children has been developed which include the new formulation of oral rehydration salts containing lower concentrations of glucose and salt (Low-Osmolarity ORS), and zinc supplementation ${ }^{1}$. Despite this innovative advance in diarrhoea management, ORS and zinc still remain underused, while antibiotics or antidiarrheals are often incorrectly administered for the management of childhood diarrhoea ${ }^{2}$.

Diarrhoea is a leading killer disease in children accounting for $9 \%$ of all deaths among children under age five worldwide ${ }^{3}$, and most deaths from diarrhoea occur in children less than 2 years of age living in South Asia and Africa ${ }^{4}$. The rate of implementation of an innovative public health policy is usually influenced by the level of knowledge of the people as well as certain social or structural barriers that may pose a threat to widespread adoption ${ }^{5}$. Also, the adoption of an innovation can only be influenced by a general awareness of the need and relative advantage of that innovation ${ }^{5}$. Hence the success in reducing morbidity and mortality due to diarrhoea depends on the rapid acceptance, adoption and accelerated use of the new WHO recommendation on diarrhoea management by the government, policymakers, health care providers and caregivers ${ }^{6}$. The Sustainable Development Goal (SDG) 3 emphasizes that diarrhoea related morbidity can be avoided through prevention, treatment and education campaign. A study carried out in Benin City revealed a gap in knowledge and practice on the use of zinc and L-ORS among health care providers ${ }^{7}$. In this study, the researchers evaluated the level of knowledge and the barriers to the use of L-ORS and zinc supplementation among primary health care providers in Imo State, Nigeria.

\section{Statement of Problem}

Over 10 years of the WHO recommendation on the use of low-ORS and zinc supplementation as the gold standard for the management of childhood diarrhoea, there is still a remarkable gap in the implementation of this life-saving intervention across the public and private health sectors in Nigeria ${ }^{8}$.

Worldwide, just over 40 per cent of children under age five with diarrhoea receive the recommended treatment ${ }^{3}$. Coverage of this treatment package is lowest in Africa and South Asia ( $38 \%$ and $47 \%$ respectively), the regions with the highest deaths from diarrhoea ${ }^{3}$.

Since the adoption of this new recommendation, limited studies have been carried out to determine the level of knowledge and barriers to the use of L-ORS and zinc supplementation among primary healthcare providers in Nigeria. This study, therefore, determined the level of knowledge on the use of low osmolarity ORS and zinc supplementation in the management of childhood diarrhoea among primary healthcare providers in Imo state, and also the barriers against its effective use. 


\section{Research Questions}

1. To what extent are healthcare providers in Imo State of Nigeria Primary Health Centres knowledgeable on the use of L-ORS and zinc supplementation in the management of childhood diarrhoea?

2. What are the perceived barriers to the use of L-ORS and zinc supplementation in the management of childhood diarrhoea among Primary Health Care providers in Imo State Nigeria?

\section{Hypotheses}

The following null hypotheses guided the study. The hypotheses were tested at a 0.05 level of significance.

1 The level of knowledge on the use of L-ORS and zinc supplementation is not significantly associated with its use by Primary Health Care providers in the management of childhood diarrhoea.

2 Significant difference does not exist across the cadre of Health Care Providers in the Primary Health Centres with regard to their use of L-ORS and Zinc supplementation in the management of childhood diarrhoea.

\section{MATERIALS AND METHODS}

\section{Research Design}

A descriptive cross-sectional design was used to determine the level of knowledge and possible barriers to effective use of L-ORS and Zinc supplementation among primary healthcare providers in Imo State, Nigeria.

\section{Population of the Study}

The population for the study consisted of 2231 health care providers including Nurses/Midwives, Community Health Extension Workers, Community Health Officers, and Health Assistants working in the government-owned Primary Health Centres (PHCs) across the 27 LGAs of Imo State. The data on Imo State PHCs and Staff distribution were obtained from the office of the Executive Secretary Imo State Primary Health Care Development Agency (September 2018).

\section{Sample and Sampling Technique:}

Multi-stage sampling involving stratified and simple random sampling techniques constituted the sampling techniques for the study. In the first stage, a proportionate selection of a number of respondents from each subgroup (LGA) was done using stratified random sampling. The second stage involved the selection of PHCs from each LGA using a simple random sampling technique and the third stage was the selection of respondents from each selected PHC using a simple random sampling technique. The total sample size of this study was 340 respondents consisting of Nurses, CHEWS, CHO's and Health Assistants. 


\section{Instrument for Data Collection}

Data were collected using a questionnaire on the use of L-ORS and zinc supplementation in the management of Childhood Diarrhoea to elicit information on the level of knowledge and the barriers to the use of L-ORS and Zinc supplementation in the management of childhood diarrhoea. The questionnaire had two sections (A and B). Section A elicited information on the respondents' demographic characteristics while section B elicited information on the knowledge and barriers to the use of Zinc and L-ORS in the Management of Childhood Diarrhoea. This section has items with "Yes or No" response options.

\section{Ethical Consideration}

A letter of introduction was obtained from the Head of the Department of Nursing Science, Nnamdi Azikiwe University, Awka (Nnewi Campus). With the introductory letter, Ethical Approval to carry out the study was sought and received from Imo State Ministry of Health. Permission to carry out the research within the State Primary Health Centres was also sought and obtained from Imo State Primary Health Care Development Agency (ISPHCDA). The letter of permission obtained from ISPHCDA was presented to the PHC Coordinators of the 27 LGAs where the study was carried out in the State. Informed consent from each respondent was obtained before administration of the instrument with their confidentiality assured.

\section{Method of Data Collection}

The letter from the office of the Executive Secretary ISPHCDA was presented to the PHC Coordinators in each LGA to facilitate access to the target population. The researchers also worked with research assistants in administering copies of the questionnaire. The research assistants were trained in the administration of the questionnaire. A total of 340 copies of the questionnaire were administered to the respondents.

\section{Method of Data Analysis}

Data on the demographic characteristics of the respondents were analysed using frequencies and percentages. knowledge of healthcare providers on the use of L-ORS and Zinc supplementation in the management of childhood diarrhoea was analysed using frequencies and percentages. The levels of knowledge were categorised into good, moderate and poor with score $80-100=$ Good, score $60-79=$ moderate, and score $<60=$ poor (table 1 ). Barriers to the use of L-ORS and Zinc was also analysed using frequencies and percentages. The hypotheses were tested using Chi-square test at a significant level of 0.05 . The analysis was done with the aid of statistical software (SPSS), version 20.0.

Table 1: Categorization of Levels of Knowledge/ Extent of use of Low ORS and Zinc

\begin{tabular}{|l|l|}
\hline Percentage of total Scores (\%) & Level (knowledge/ Extent of Use) \\
\hline Score of $80-100$ & Good \\
\hline Score of $60-79$ & Moderate \\
\hline Score $<60$ & Poor \\
\hline
\end{tabular}




\section{RESULTS}

Socio-demographic Characteristics of the Study Population

Table 2: Socio-demographic Characteristics of the Study Population

\begin{tabular}{|c|c|c|c|}
\hline $\mathbf{S} / \mathbf{N}$ & Factors & Frequency $(\mathrm{N}=340)$ & Percentages \\
\hline \multirow[t]{6}{*}{ A } & Age (years) & & \\
\hline & $20-29$ & 31 & 9.12 \\
\hline & $30-39$ & 141 & 41.47 \\
\hline & $40-49$ & 118 & 34.70 \\
\hline & $50-59$ & 46 & 13.53 \\
\hline & $>60$ & 4 & 1.18 \\
\hline \multirow[t]{3}{*}{ B } & Gender & & \\
\hline & Male & 35 & 10.29 \\
\hline & Female & 305 & 89.71 \\
\hline \multirow[t]{5}{*}{$\mathrm{C}$} & Cadre & & \\
\hline & Registered Nurse & 85 & 25.00 \\
\hline & CHEW/JCHEW & 139 & 40.88 \\
\hline & $\mathrm{CHO}$ & 52 & 15.29 \\
\hline & HA/Attendant & 64 & 18.83 \\
\hline \multirow[t]{6}{*}{$\mathrm{D}$} & Years of Experience & & \\
\hline & 6 months-1year & 15 & 4.41 \\
\hline & $2-5$ years & 45 & 13.24 \\
\hline & 6-10years & 118 & 34.71 \\
\hline & 11-20years & 105 & 30.88 \\
\hline & $>20 y e a r s$ & 57 & 16.76 \\
\hline \multirow[t]{4}{*}{$\mathrm{E}$} & Location of Facility & & \\
\hline & Rural & 221 & 65.00 \\
\hline & Semi-Urban & 73 & 21.47 \\
\hline & Urban & 46 & 13.53 \\
\hline
\end{tabular}

Table 2 shows that the highest age distribution among the respondents was 30-39 years with $41.47 \%$ (141), followed by age 40-49 years: $34.70 \%$ (118). The least number of respondents were above 60 years of age and they constituted $1.18 \%$ (4) of the respondents. The male respondents were $35(10.29 \%)$ while the females were $305(89.71 \%)$. The cadre of healthcare providers that participated in the study were Registered nurses, CHEW/JCCHEW, CHOs, and HA/Attendants with CHEW/JCCHEW constituting the highest number: 139 (40.88\%). The respondents with 6-10 years experience were highest: $118(34.71 \%)$. Health facilities in the rural areas constituted the highest: 221 (65\%), followed by semi-urban: 73(21.47\%), and lastly the urban areas: $46(13.53 \%)$. 
Table 3: Responses to the level of Knowledge on use of L-ORS and zinc supplementation among health care providers

\begin{tabular}{|c|c|c|c|c|c|c|}
\hline $\mathbf{S} / \mathbf{n}$ & Items & $\begin{array}{c}\text { Res } \\
\text { pon } \\
\text { Ses } \\
\end{array}$ & Freq & \%age & $\begin{array}{c}\text { Mean score of } \\
\text { Responses } \\
(\%) \\
\end{array}$ & Category \\
\hline 1 & Have heard of L-ORS and Zinc & $\begin{array}{l}\text { No } \\
\text { Yes }\end{array}$ & $\begin{array}{c}15 \\
325\end{array}$ & $\begin{array}{l}4 \% \\
96 \%\end{array}$ & 96 & Good \\
\hline 2 & $\begin{array}{l}\text { L-ORS and Zinc is sufficient to } \\
\text { treat uncomplicated diarrhoea }\end{array}$ & $\begin{array}{l}\text { No } \\
\text { Yes }\end{array}$ & $\begin{array}{c}71 \\
269\end{array}$ & $\begin{array}{l}21 \% \\
79 \%\end{array}$ & 79 & Moderate \\
\hline 3 & $\begin{array}{l}\text { Composition of L-ORS is the } \\
\text { same as standard ORS }\end{array}$ & $\begin{array}{l}\text { No } \\
\text { Yes }\end{array}$ & $\begin{array}{c}62 \\
278\end{array}$ & $\begin{array}{l}18 \% \\
82 \%\end{array}$ & 18 & Poor \\
\hline 4 & $\begin{array}{l}\text { Start L-ORS and Zinc for all } \\
\text { cases of diarrhoea }\end{array}$ & $\begin{array}{l}\text { No } \\
\text { Yes }\end{array}$ & $\begin{array}{c}40 \\
300\end{array}$ & $\begin{array}{l}12 \% \\
88 \%\end{array}$ & 88 & Good \\
\hline 5 & $\begin{array}{l}\text { L-ORS and Zinc are effective to } \\
\text { reduce the severity and duration } \\
\text { of diarrhoea }\end{array}$ & $\begin{array}{l}\text { No } \\
\text { Yes }\end{array}$ & $\begin{array}{c}47 \\
293\end{array}$ & $\begin{array}{l}14 \% \\
86 \%\end{array}$ & 86 & Good \\
\hline 6 & $\begin{array}{l}\text { For a } 10 \text { month old with } \\
\text { diarrhoea, use } 20 \mathrm{mg} \text { of Zinc } \\
\text { once daily for } 10 \text { to } 14 \text { days. } \\
\text { L-ORS prevents dehydration } \\
\text { and reduces stool output \& Zinc } \\
\text { reduces diarrhoea prevalence } \\
\text { Overall/Average Knowledge }\end{array}$ & $\begin{array}{l}\text { No } \\
\text { Yes }\end{array}$ & $\begin{array}{c}38 \\
302\end{array}$ & $\begin{array}{l}25 \% \\
75 \%\end{array}$ & $\begin{array}{c}89 \\
\mathbf{7 5 . 8 6}\end{array}$ & $\begin{array}{c}\text { Good } \\
\text { Moderate }\end{array}$ \\
\hline
\end{tabular}

In table 3,96\% of respondents have heard of L-ORS and zinc supplementation, $79 \%$ of them knew that L-ORS and Zinc are sufficient to treat uncomplicated diarrhoea. Only $18 \%$ of respondents knew that the composition of L-ORS is not the same as the standard ORS, while $82 \%$ of respondents still had the wrong perception that the composition of L-ORS is the same as standard ORS. $88 \%$ of respondents indicated that L-ORS and zinc supplementation should be initiated as first-line treatment for all cases of diarrhoea in children, and $86 \%$ knew that LORS and Zinc are effective to reduce the severity and duration of diarrhoea. Only $75 \%$ of the respondents knew the correct prescription of zinc supplementation in children, even though 89\% indicated that L-ORS prevent dehydration and reduces stool output \& Zinc reduces diarrhoea prevalence in children. The average score for responses to the level of knowledge was $75.86 \%$, indicating a moderate level of knowledge among health care providers. 
African Journal of Biology and Medical Research

ISSN: $2689-534 \mathrm{X}$

Volume 4, Issue 3, 2021 (pp. 79-91)

www.abjournals.org

Table 4: Perceived Barriers to the Use of L-ORS \& Zinc supplement

\begin{tabular}{|c|c|c|}
\hline \multirow[t]{2}{*}{ Items } & \multicolumn{2}{|c|}{ Status $[\mathbf{f}(\%)]$} \\
\hline & Yes & No \\
\hline 11. Limited training and re-training of HCWs & $207(60.9)$ & $133(39.1)$ \\
\hline 12. Poor knowledge on use of L-ORS \& zinc & $98(28.8)$ & $242(71.2)$ \\
\hline 13. Un-availability of L-ORS and Zinc supplementation & $292(85.9)$ & $48(14.1)$ \\
\hline 14. High cost of buying L-ORS and Zinc supplementation & $128(37.6)$ & $212(62.4)$ \\
\hline 15. Lack of acceptance by caregivers & $118(34.7)$ & $222(65.3)$ \\
\hline 16. Poor communication of current & & \\
\hline Public health Trends among health providers & $277(81.5)$ & $63(18.5)$ \\
\hline
\end{tabular}

Table 4 shows that limited training and re-training of health care workers $(60.9 \%)$, Poor knowledge on the use of Zinc and L-ORS in the management of childhood diarrhoea (28.8\%), unavailability of L-ORS and Zinc supplementation (85.9\%), high cost of buying zinc and LORS (37.6\%), lack of acceptance of Zinc and L-ORS by parents or caregivers (34.7\%), and poor communication of current public health trends among health providers $(81.5 \%)$ were the barriers to the use of L-ORS and zinc supplementation as perceived by the primary healthcare providers.

\section{Hypotheses Testing}

Table 5: Chi-square tests comparisons of Knowledge and Cadre of Healthcare Providers in relation to their Use of L-ORS and zinc supplementation

\begin{tabular}{|c|c|c|c|c|c|c|}
\hline \multirow{3}{*}{$\begin{array}{l}\text { Variable } \\
\text { Knowledge }\end{array}$} & \multirow[b]{2}{*}{ Category } & \multicolumn{3}{|c|}{ Usage (f (\%)) } & \multirow[t]{2}{*}{$\mathbf{X}^{2}$} & \multirow[t]{2}{*}{$\mathbf{P}$} \\
\hline & & Poor & Moderate & Good & & \\
\hline & Poor & $6(54.5)$ & $\begin{array}{c}5(45.5) \\
113\end{array}$ & $0(0.0)$ & 12.59 & $0.01 *$ \\
\hline \multirow{7}{*}{ Cadre } & Moderate & $68(34.0)$ & $(56.5)$ & $19(9.5)$ & & \\
\hline & Good & $32(24.8)$ & $71(55.0)$ & $26(20.2)$ & & \\
\hline & Registered & & & & & $<0.01$ \\
\hline & Nurse/Midwife & $12(14.1)$ & $51(60.0)$ & $22(25.9)$ & 25.72 & $*$ \\
\hline & CHEW/JCHEW & $53(38.1)$ & $72(51.8)$ & $14(10.1)$ & & \\
\hline & $\mathrm{CHO}$ & $17(32.7)$ & $31(59.6)$ & $4(7.7)$ & & \\
\hline & $\begin{array}{l}\text { Health Assistant/ } \\
\text { Attendant }\end{array}$ & $24(37.5)$ & $35(54.7)$ & $5(7.8)$ & & \\
\hline
\end{tabular}

*statistically significant at $\mathbf{0 . 0 5}$ level 
Hypotheses 1: Level of knowledge on the use of L-ORS and zinc supplementation is not significantly associated with its use by primary health care providers in the management of childhood diarrhoea.

Table 5 shows that the $\mathrm{X}^{2}$ was 12.59 with a p-value of 0.01 . Since the $P$-value $\left(0.01^{*}\right)$ was less than the $\alpha$-level, the null hypothesis was therefore rejected. Level of knowledge on the use of L-ORS and zinc supplementation was significantly associated with its use by primary health care providers in the management of childhood diarrhoea.

Hypothesis 2: Significant difference does not exist across the cadre of Health Care Providers in the Primary Health Centres with regard to their use of L-ORS and Zinc supplementation in the management of childhood diarrhoea.

Table 5 also shows $X^{2}=25.72 ; \mathrm{p}$-value $<0.01$. Since the $P$-value $(<0.01 *)$ was less than the $\alpha$ level, the null hypothesis was therefore rejected. Significant differences existed across the cadre of health care providers in the primary health centres with regard to their use of L-ORS and zinc supplementation in the management of childhood diarrhoea.

A multiple regression analysis (MRA) was further used to assess the strength of the relationship tested in the hypotheses (the use of L-ORS and zinc in relation to other predictor variables).

Table 6: Predictors of L-ORS and Zinc Supplementation Usage.

\begin{tabular}{llll}
\hline Variable & OR (estimate) & $\mathbf{9 5 \%}(\mathbf{C I})$ & p-Value \\
\hline Knowledge & & & \\
Poor & 1.00 & & \\
Moderate & 2.33 & $0.69-7.91$ & 0.1751 \\
Good & 3.64 & $1.04-12.73$ & $0.0433^{*}$ \\
Cadre & & & \\
RN/MW & 3.65 & $1.65-8.07$ & $0.0014^{*}$ \\
CHEW/JCHEW & 0.97 & $0.53-1.79$ & 0.9316 \\
CHO & 1.24 & $0.57-2.67$ & 0.5903 \\
Health Attendants & 1.00 & & \\
\hline
\end{tabular}

\section{*Significant at 0.05 level}

As presented in Table 6, respondents with moderate knowledge of L-ORS were about twice more likely to use L-ORS compared with those with poor knowledge though this failed to reach statistical significance $(\mathrm{OR}=2.33, \mathrm{p}=0.1751)$. Unlike moderate knowledge, good knowledge was an independent predictor of L-ORS usage in this study $(\mathrm{OR}=3.64, \mathrm{p}=0.0433)$.

Being a registered nurse/midwife was an independent predictor of L-ORS usage and these cadres of respondents were about four times likely to use L-ORS compared to other categories of health workers in this study $(\mathrm{OR}=3.65, \mathrm{p}=0.0014)$. 


\section{DISCUSSION OF FINDINGS}

\section{Research Question 1: To what extent are healthcare providers in primary health centres knowledgeable on the use of L-ORS and zinc supplementation in the management of childhood diarrhoea?}

Findings from the study revealed a moderate level of knowledge $(75.86 \%)$ among healthcare providers on the use of L-ORS and zinc supplementation in the management of childhood diarrhoea (Table 3). Despite the moderate level of knowledge among health providers, a significant number $(82 \%)$ of them had poor knowledge on the specific difference in composition between the new L-ORS and the standard ORS. This indicates that health care workers in primary health centres in Imo state still have an identifiable knowledge gap on some essential innovative components supporting the use of L-ORS and zinc supplementation in the management of childhood diarrhoea. The Low Osmolarity ORS (L-ORS) was made by reducing the solution's glucose concentration to $75 \mathrm{mmol} / \mathrm{L}$, its salt $(\mathrm{NaCl})$ concentration to $75 \mathrm{mEq} / \mathrm{L}$ and its total osmolarity to $245 \mathrm{mOsm} / \mathrm{L}$ as against the standard ORS containing 90 $\mathrm{mEq} / \mathrm{l}$ of sodium with a total osmolarity of $311 \mathrm{mOsm} / \mathrm{L}^{1}$. This L-ORS formulation is more adaptable in children and has been found to be associated with less volume, less stool output and reduced need for unscheduled intravenous fluid when compared with the standard ORS ${ }^{1}$. Recent studies suggest that the administration of zinc along with new low osmolarity oral rehydration salt (L-ORS) can reduce the duration and severity of diarrheal episodes for up to three months ${ }^{9}$. Majority of the health care workers in this study however knew at least one benefit associated with the use of zinc supplementation when managing diarrhoea in children (table 3). The finding from this study agrees with the findings from a similar study in Benin City, which showed that $67 \%$ of health care workers were knowledgeable of zinc supplementation but specific knowledge of zinc supplementation, such as accurate prescription and mode of action of zinc when used in the management of childhood diarrhoea was poor ${ }^{7}$. Also, in another study that reflected a high level of knowledge among providers and caregivers, this high level of knowledge was however preceded by a training a few months before the assessment $^{10}$.

\section{Research Question 2: What are the perceived barriers to the use of L-ORS and zinc in the management of childhood diarrhoea among primary health care providers?}

From the results presented in table 4, the common barriers contributing to the suboptimal use of L-ORS and zinc in the management of diarrhoea in children included limited training and re-training of health care workers $(60.9 \%)$, which was highlighted as one of the major contributing factors to poor implementation. It has been established that training and retraining programs motivate health care providers and promotes rapid implementation and sustenance of best practices in the health care system. More so, training workshops for health care providers presents an excellent opportunity to review the basic diarrhoea control strategies in addition to the current guidelines by the $\mathrm{WHO}^{11}$. This is particularly most important for PHC workers who are usually the first level of contact with individuals in the community and have a unique one-on-one opportunity to influence compliance to treatment recommendations including zinc supplementation and L-ORS use ${ }^{7}$. Adequate knowledge would ensure appropriate prescription of zinc in all diarrhoeal cases and prevent irrational prescription? Delivery of these life-saving interventions needs knowledgeable health workers who have access to frequent refresher training on the key interventions that they deliver ${ }^{10}$. A study on a Public Health Partnership for Introduction of Zinc for diarrhoea treatment in Benin recorded 
that health care workers who had received formal training on the use of zinc supplementation in the management of childhood diarrhoea prescribed it more ${ }^{12}$. Poor availability of L-ORS and Zinc supplementation was also identified as a barrier (85.9\%) due to irregular supply by the government or donor agencies; poor acceptance of zinc and L-ORS by caregivers $(34.7 \%)$ was equally identified as a barrier to its use in the management of childhood diarrhoea, although to a low extent ${ }^{12}$. Researchers ${ }^{13}$ have also reported that the major constraints to the utilization of ORS and zinc among caregivers were a taste of zinc and inadequate information. Evidence has shown that zinc treatment is effective and generally safe in children; the only known side effect of zinc supplementation is vomiting which is rarely reported and is typically attributed to the metallic taste in the tablet. More so, the use of high-quality tablets can avert this side effect $^{14}$. Poor communication of current public health trends among health providers $(81.5 \%)$ (Table 4) was identified in this study as the most common barrier to the adoption and scale-up of an evidence-based public health policy such as the use of L-ORS and Zinc in the management of childhood diarrhoea. To maximize the impact of public health interventions found to be effective in improving health, there is a need for rapid diffusion, adoption and promotion of such interventions on a population-wide basis ${ }^{15}$ and this can be achieved through interpersonal networks and communications of current public health interventions and practices among health care providers. With a balanced promotion strategy, it is expected that the combination of zinc and low osmolarity ORS will meet the expectations of both providers and caregivers, resulting in a better acceptance and utilisation for the management of childhood diarrhoea ${ }^{16}$.

\section{Hypotheses}

Finding from the study showed that the level of knowledge on the use of L-ORS and zinc supplementation was significantly associated with its use by primary health care providers in the management of childhood diarrhoea (p-value 0.01) (table 5). A study carried out in India showed that the practice of prescribing zinc and ORS for diarrhoea treatment among children under five was positively influenced by zinc and ORS knowledge ${ }^{17}$. Recent efforts to promote the use of ORS and zinc for diarrhoea treatment in some countries show that substantial progress is possible with specific interventions aimed at improving the knowledge of health care providers. In six districts in the Indian State of Gujarat and twelve districts of Uttar Pradesh pilot program, Diarrhea Alleviation through Zinc Therapy (DAZT) during 2011-2014, trained and supported public sector providers, made individual educational visits including the informal rural practitioners who provide the majority of the care and worked to ensure supply of ORS and zinc at community leve ${ }^{17}$. In the Gujarat districts, the use of both ORS and zinc increased from $2 \%$ to $18 \%$, implying that the combined intervention of improving knowledge and ensuring supplies contributed to increased use. On the other hand, in the districts of Uttar Pradesh, ORS and zinc use remained suboptimal despite the interventions ${ }^{17}$. Deductions made from this study also brings to bear the fact that improved knowledge and availability of zinc and ORS supplies may not necessarily improve its use in the management of diarrhoea, other factors could also be inferred. Studies have also revealed a gap in the knowledge and practice of the use of zinc and low ORS in the management of diarrhoea in children. Specific knowledge on the use of zinc supplementation in the management of childhood diarrhoea among health care providers was poor and this affected the use of zinc and ORS in the management of childhood diarrhoea, implying an association between knowledge and use of zinc and low ORS $^{7}$. 
In a study carried out to determine the treatment patterns of childhood diarrhoea among health care providers in rural Uganda, healthcare providers were found to lack relevant knowledge on the use of zinc and low ORS for the management of diarrhoea in under 5 children, only ORS was seen to be used in majority of the cases and zinc was not prescribed or recommended in any case ${ }^{18}$. Knowledge on ORS was seen to greatly affect its use in the management of childhood diarrhoea, however, the majority of staff across the health centres stated that they also prescribed antibiotics for common diarrhoea. There was a significant difference in the use of L-ORS and zinc supplementation for the management of childhood diarrhoea across the various cadre of health care providers as Nurses were reported to demonstrate a higher level of use when compared to other healthcare workers. In a study carried out to assess the capacity of community health workers on the current management of childhood diarrhoea in Jigawa State, Nigeria, Nurses were seen to give more L-ORS and Zinc to children with diarrhoea than CHOs and CHEWs, even though there was no statistically significant difference in the level of knowledge across the various cadre of health care providers ${ }^{19}$. Studies among private and public health care providers in India have also shown no significant difference in the use of LORS and zinc supplementation for the management of childhood diarrhoea across the various cadre of health care providers in the primary health centres, as most of the providers across all cadres correctly described how to prepare ORS, and nearly all (90 to 100\%) reported routinely prescribing it to treat diarrhoea in children ${ }^{20}$. Among the few providers who reported ever not recommending zinc, the two most frequently reported reasons for not doing so were not completely understanding zinc for diarrhoea treatment and not having zinc in stock at the time of contact with the patient ${ }^{20}$.

\section{CONCLUSION}

Knowledge of primary healthcare providers on the use of low osmolarity oral rehydration solution and zinc supplementation in the management of childhood diarrhoea among primary health care providers in Imo state was suboptimal. Level of knowledge and cadre of the primary healthcare providers were significantly associated with their use of L-ORS and zinc supplementation in the management of childhood diarrhoea. It is imperative to note that constant training and retraining of health care workers on current public health best practices especially with respect to the integrated management of childhood illnesses such as diarrhoea, will help to overcome the barriers to the use of L-ORS and zinc as well as improve the rate of adoption and implementation of best practices among health care providers at the grassroots.

\section{REFERENCES}

[1] World Health Organization. (2005). The Treatment of Diarrhea: A Manual for Physicians and Other Senior Health Workers. Geneva: Author.

[2] Zwister G, Simpson E, Moodley M. (2013). Treatment of Diarrhoea in Young Children: Results from Surveys on the Perception and Use of Oral Rehydration Solutions, Antibiotics, and Other Therapies in India and Kenya. J Glob Health 2013 June; 3(1): 010403. 
[3] UNICEF. (2016). Global Databases based on DHS, MICS and other Nationally Representative Sources. Retrieved from https://www.unicef.org/statistics/index_24302.html

[4] UNICEF, WHO. (2009). Diarrhoea: Why Children Are Still Dying and what can be done. Geneva. UNICEF/ WHO Press.

[5] Rogers E M. (2003). Diffusion of Innovations ( $5^{\text {th }}$ ed.). New York: Free Press

[6] World Health Organization and United Nation Children. (2004). Joint Statement on Clinical Management of Diarrhoea. (WHO/FCH/CAH/04.07/PD/Diarrhoea/OL). Geneva and New York: WHO and UNICEF Fund

[7] Omenumu V O, Ofuani J O, Kubeyinje I C. (2012). Knowledge and Use of Zinc Supplementation in the Management of Childhood Diarrhoea among Health Care Workers in Public Primary Health Facilities in Benin-City, Nigeria. Global Journal of Health Sci, 4(2).

[8] World Health Organization. (2015). Bridging the "know-do" Gap Meeting on Knowledge Translation in Global Health. Retrieved from http://www.who.int/kms/WHO_EIP_KMS_2006_2.pdf Accessed July 2015.

[9] Bhutta Z, Nelson E, Lee W, Tarr P, Zablah R, Phua K. (20118). Recent Advances and Evidence Gaps in Persistent Diarrhea. J Pediatr Gastroenterol Nutr. 47 (2): 260-5.

[10] Kung' u' J K, Owolabi O, Essien G, Aminu F T, Ngnie-Teta I, Neufeld L M. (2015). Promotion of Zinc Tablets with ORS through Child Health Weeks Improve Caregiver Knowledge, Attitude and Practice on Treatment of Diarrhoea in Nigeria. J Health Popul Nutr. 33 (1): 9:19.

[11] USAID. (2005), Guidelines for New Diarrhoea Treatment Protocols for CommunityBased Healthcare Workers, Retrieved from https://www.shopsplusproject.org/sites/default/files/resources/2789_file_CHW guidelines.pdf

[12] Mac-Donald E, Moralejo D G, Mathew M K. (2007). Maternal Understanding of Diarrhoea - Related Dehydration and its Influences on ORS Use in Indonesia. Asia Pacific of Public Health, 19(1), 34-39.

[13] Olatona FA, Obrutu OE, Adeniyi OF. (2016). Home Management of Childhood Diarrhoea Including Zinc Supplementation among Mothers Attending Primary Health Centre in Urban Community in Lagos. The Tropical Journal of Health Sciences, Vol. 23(2), 23-29.

[14] Larson C P, Hoque AB, Larson C P, Khan AM, Saha U R. (2005). Initiation of Zinc Treatment for Acute Childhood Diarrhoea and Risk for Vomiting or Regurgitation: a randomized, double-blind, placebo-controlled trial. J Health Popul Nutr. 23:311-9.

[15] Haines A, Kuruvilla S, Borchert M. (2004). Bridging the Implementation Gap between Knowledge and Action for Health. Bull World Health Org. 82: 724-33.

[16] Olufemi GO, Tajudeen R, Olumuyiwa AO, Kola MA. (2012). Knowledge, Attitude and Practice of Home Management of Childhood Diarrhoea among caregivers of Under-5 Children with Diarrhoeal Disease in North-Western Nigeria. Journal of Tropical Pediatrics, 58 (2), 143-146. Retrieved from https://doi.org/10.1093/tropej/fmr048

[17] Lamberti LM, Taneja S, Mazumder S, LeFevre A, Black R E, Walker C L. (2015). An External Evaluation of the Diarrhea Alleviation through Zinc and ORS Treatment (DAZT) Program in Gujarat and Uttar Pradesh, India. J Glob Health, (5), https://www.ncbi.nlm.nih.gov/pmc/articles/PMC4676588/ 
African Journal of Biology and Medical Research

ISSN: $2689-534 \mathrm{X}$

Volume 4, Issue 3, 2021 (pp. 79-91)

www.abjournals.org

[18] Lofgren J, Tao W, Larsson E, Kyakulaga F, Forsberg B. (2012). Treatment Pattern of Childhood Diarrhoea in Uganda: A Cross-Sectional Survey. BMC International Health and Human Rights. 12:19.

[19] Abdu HA, Olosunde ZO, Awogbenja MD, Zango AA. (2013) Assessing the capacity of Community Health Workers on the Current Management of Childhood Diarrhoea in Jigawa State, Nigeria. Jos Journal of Medicine, 7(1).

[20] Walker C L, Taneja S, LeFevre A, Black R E, Mazumder S. (2015). Appropriate Management of Acute Diarrhea in Children among Public and Private Providers in Gujarat, India: A Cross-SectionalSurvey. Glob Health Sci Pract. May 7;3(2):230-41 